\title{
Sequencing Analysis of Partial $N$ gene of Feline Morbillivirus from Malaysia
}

\author{
Siti Tasnim Makhtar ${ }^{1}$, Sheau Wei Tan ${ }^{2}$, Abdul Rahman Omar ${ }^{1,2}$ and \\ Farina Mustaffa-Kamal ${ }^{1,2 *}$ \\ ${ }^{1}$ Faculty of Veterinary Medicine, Universiti Putra Malaysia, 43400 Serdang, Malaysia \\ ${ }^{2}$ Institute of Bioscience, Universiti Putra Malaysia, 43400, Serdang, Malaysia
}

\begin{abstract}
Feline morbillivirus (FeMV) is a new emerging virus of domestic cats categorized under the genus of Morbillivirus, associated with chronic kidney disease (CKD). The origin of the virus is yet to be determined, and whether it is caused by a spill-over event from wildlife or domestic cats remains speculative. Recombination event has been reported in FeMV isolate found in Japan; therefore, characterization of FeMV strains isolated in Malaysia (i.e., FeMV-Malaysia isolates) may provide some insight, thus adding some information on the viral evolution of FeMV. Therefore, this study aims to conduct a phylogenetic analysis and assess any genetic changes in the $N$ gene of FeMV-Malaysia isolates. Through sequencing of $N$ gene of seven isolates using three overlapping primer sets, the sequences spanning approximately $1.5 \mathrm{~kb}$ of FeMV- $N$ gene were obtained. DNA sequencing, nucleotide sequences, amino acid residues alignments, and phylogenetic analysis were performed. A nucleotide sequence alignment was also performed to compare the isolates obtained from two previous studies. From the alignment mentioned above, there were 19 variable sites of which there were absence of amino acid changes except for isolate UPM210 at position 806 and isolate UPM315 at position 823. Furthermore, protein alignment was done to compare FeMV-Malaysia isolates with FeMV strains from other countries, along with other morbillivirus-

ARTICLE INFO

Article history:

Received: 13 September 2021

Accepted: 24 December 2021

Published: 10 February 2022

DOI: https://doi.org/10.47836/pjtas.45.1.20

E-mail addresses:

tasnimakhtar82@gmail.com (Siti Tasnim Makhtar)

tansheauwei@gmail.com (Sheau Wei Tan)

aro@upm.edu.my (Abdul Rahman Omar)

farina@upm.edu.my (Farina Mustaffa-Kamal)

* Corresponding author related isolates. From one of the conserved regions located within the $N$ gene, similar amino acid sequences were detected across different morbilliviruses. Lastly, from the phylogenetic tree, it was illustrated that all partial FeMV-N gene Malaysia isolates sequenced in this study were clustered together in the same clade whereby these FeMV- $N$ genes Malaysia isolates shared a
\end{abstract}


common ancestor with isolates from Japan (SS3, MiJP003, ChJP073) and Thailand (Thai-U16, CTL16. CTL43).

Keywords: Feline morbillivirus, partial $N$ gene, sequencing analysis

\section{INTRODUCTION}

Feline morbillivirus (FeMV) is a nonsegmented, negative-sense, single-stranded RNA morbillivirus that was first discovered in Hong Kong in 2012, and it has been speculated to cause chronic kidney disease (CKD) in domestic cats (Woo et al., 2012). It forms a distinct species under the genus Morbillivirus, with nucleotide identities less than $80 \%$ of the known paramyxoviruses. Similar to other paramyxoviruses and morbilliviruses, the genome organization of FeMV follows the rule of six, where it efficiently replicates when there are six nucleotides in length. In addition, the gene organization of FeMV ( 3 ' $-N-P / V / C$ $M-F-H-L-5$ ') is similar to that of other morbilliviruses.

Nucleoprotein $(\mathrm{N})$, which is translated from the $N$ gene, plays a crucial role in the transcription of the virus (Sourimant \& Plemper, 2016). The RNA-dependent RNA polymerase $(\mathrm{RdRp})$ will synthesize the viral RNA only when encapsidated by the $\mathrm{N}$ protein as a template. Both polymeraseassociated phosphoprotein $(P)$ and large $(L)$ genes, which are involved in all polymerase activities, are responsible for forming the RdRp complex and the $\mathrm{N}$ protein. In addition, two glycoproteins, which are the fusion (F) and haemagglutinin $(\mathrm{H})$ proteins, make up the outer layer or envelope of the virus that connects to the matrix $(\mathrm{M})$ protein surrounding the ribonucleoprotein (Rima et al., 2019).

Genetic changes in a virus could be identified by performing sequences alignment of the nucleotide or amino acid residue. Genetic changes of a virus may include mutation and recombination (Fleischmann, 1996). Compared to DNA viruses, RNA viruses hold a higher mutation due to a lack of proofreading function in their replication enzymes. Recombination of FeMV within $F$ and $H$ genes has reported that the FeMV-Japan strains (MiJP003) could probably originate from recombination between two FeMV parental strains that are closely related to Japan (ChJP073) and Hong Kong (776U) isolates (Park et al., 2014). Hence, any genetic changes that might have occurred in the $N$ gene of FeMVMalaysia isolates could be investigated through this work.

\section{MATERIALS AND METHODS}

\section{Sample for Sequencing Analysis}

Samples for sequencing analysis $(n=7)$ were obtained as part of two studies to determine the molecular prevalence of FeMV in Malaysia and the development of TaqMan-based reverse-transcriptase polymerase chain reaction (RT-PCR) assay targeting the FeMV- $N$ gene (Makhtar et al., 2021; Mohd Isa et al., 2019). Briefly, the urine sample was collected from cats either by manual compression or cystocentesis. The collected urine was then placed into a 
sterile sample collection bottle and stored at $4^{\circ} \mathrm{C}$ prior to processing. The debris in the urine was removed by centrifugation at $2,320 \times g$, where the supernatant was obtained, mixed at a ratio of $1: 1$ with RNAlater ${ }^{\circledR}$ solution (Ambion, USA), and stored at $-20^{\circ} \mathrm{C}$ prior to RNA extraction.

\section{Total RNA Extraction}

Total RNA extraction for collecting urine samples was performed by using the Direct$\mathrm{zol}^{\mathrm{TM}}$ RNA MiniPrep Plus Kit according to the manufacturer's recommendation (Zymo Research, USA). Briefly, the TRI Reagent ${ }^{\circledR}$ solution was added into each sample at a ratio of 3:1 and mixed thoroughly for $5 \mathrm{~min}$. Next, an equal volume of ethanol (95\%-100\%) was added to the mixture and vortexed thoroughly. The mixture was then transferred into a Zymo-Spin ${ }^{\text {TM }} 111 C G$ Column attached to a collection tube and centrifuged at $12,000 \times g$ for $1 \mathrm{~min}$. The flow-through was discarded, and the column was transferred into a new collection tube. Next, a volume of $400 \mu \mathrm{L}$ of Direct-zol ${ }^{\mathrm{TM}}$ RNA PreWash was added into the column and centrifuged at $12,000 \times g$ for $1 \mathrm{~min}$, upon which the flow-through was discarded. This step was repeated, followed by the addition of $700 \mu \mathrm{L}$ of RNA Wash Buffer to the column and centrifugation at $12,000 \times g$ for $2 \mathrm{~min}$. The column was then transferred into an RNase-free tube, followed by the elution step repeated twice by adding a volume of $20 \mu \mathrm{L}$ of RNase-Free Water to the column matrix and centrifuged at 12,000 $\times g$ for $1 \mathrm{~min}$.

\section{cDNA Synthesis}

Extracted RNA was converted into cDNA prior to conventional RT-PCR assay. The cDNA synthesis was conducted using the SensiFAST ${ }^{\mathrm{TM}}$ cDNA Synthesis Kit (Bioline, United Kingdom) following the suggested protocol: $25^{\circ} \mathrm{C}$ for $10 \mathrm{~min}$ in primer annealing step, $42^{\circ} \mathrm{C}$ and $48^{\circ} \mathrm{C}$ each for $15 \mathrm{~min}$ in reverse transcription step, and $85^{\circ} \mathrm{C}$ for $5 \mathrm{~min}$ in inactivation step. The cDNA templates were stored at $-20^{\circ} \mathrm{C}$ prior to conventional RT-PCR analysis.

\section{FeMV-N Gene Amplification by RT- PCR and Sequencing of $N$ Gene}

Conventional RT-PCR was performed using MyTaq ${ }^{\mathrm{TM}}$ Red Mix (Bioline, United Kingdom) on the seven FeMV-positive urine samples (UPM23, UPM52, UPM53, UPM210, UPM231, UPM305, and UPM315). RNase-free water (Promega, USA) was used as a negative control in each PCR run. Three different primers were used to obtain the full sequence of the FeMV-N gene from Malaysian isolates (Figure 1). The first primer set $\left(1 \mathrm{~F}_{-} 16\right.$ and $\left.1 \mathrm{R} \_8\right)$ covering the early region of the $N$ gene was designed using the PrimerQuest tool from Integrated DNA Technologies (IDT) website based on the alignment sequences from Thailand (Thai-U16), China isolates (M252A), and Japan isolates (ChJP073, MiJP003, and SS3) (Table 1). The second (FN-2F and FN-2R) and third (FN-3F and FN-3R) primer sets targeting the middle and end regions of the $N$ gene in this study, respectively, were published primers (Park et al. (2014). The amplification 
was performed in a thermal cycler using different annealing temperatures for each primer set (Table 2). Amplified PCR product was analyzed on $1.5 \%$ agarose gels and visualized using a UV transilluminator (Syngene, United Kingdom). The PCR products were then purified and sequenced on an ABI PRISM 3730xl Genetic Analyzer (Applied Biosystems, USA) utilizing both forward and reverse primers described in this study (Table 1).

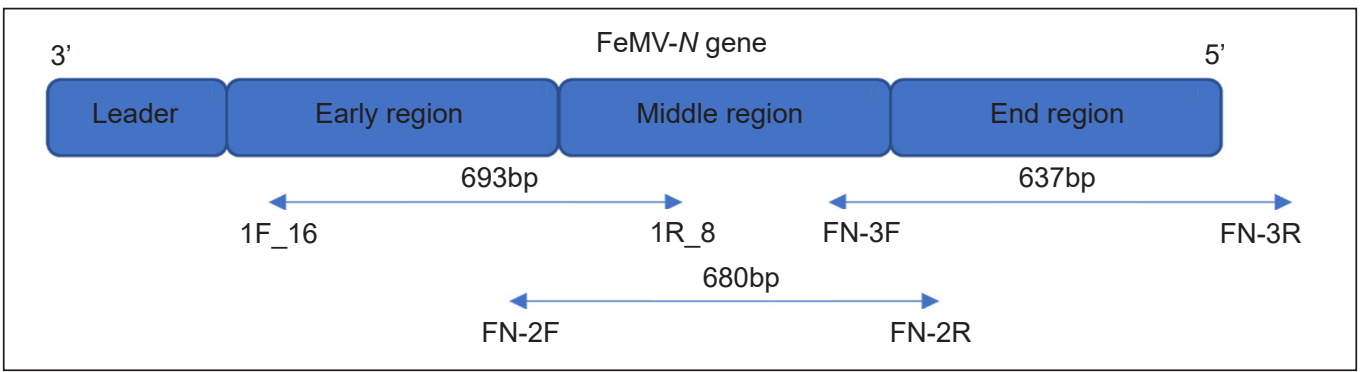

Figure 1. Schematic diagram on $N$ gene primer design. Three different sets of overlapping primers were designed to obtain a $\sim 1.5 \mathrm{~kb}$ sequence of the $N$ gene. Both primers set FN-2 (FN-2F and FN-3R) and FN-3 (FN-3F and FN-3R) were obtained from a previous study by Park et al. (2014), whereas 1F-16 and 1R-8 were newly designed primer sets

Table 1

Primer sequences were used to amplify three different regions targeting the $\mathrm{N}$ gene

\begin{tabular}{|c|c|c|c|c|}
\hline Region & Primer & Sequence (5'-3') & Product size (bp) & Source \\
\hline $\begin{array}{l}\text { Early } \\
\text { region }\end{array}$ & $\begin{array}{l}1 F_{-} 16 \\
1 \mathrm{R} \_8\end{array}$ & $\begin{array}{c}\text { CTGAAATCACTTGCCGCATTTA } \\
\text { TGCCACCATGAATCGTCTTAT }\end{array}$ & 693 & This study \\
\hline $\begin{array}{l}\text { Middle } \\
\text { region }\end{array}$ & $\begin{array}{l}\text { FN-2F } \\
\text { FN-2R }\end{array}$ & $\begin{array}{c}\text { GTTAGCTTAGGATTTGAGAACCC } \\
\text { CACCATCTCTTGACCAAGTCT }\end{array}$ & 680 & (Park et al. \\
\hline $\begin{array}{l}\text { End } \\
\text { region }\end{array}$ & $\begin{array}{l}\text { FN-3F } \\
\text { FN-3R }\end{array}$ & $\begin{array}{c}\text { GCTATGGAGTTATGCCATGGG } \\
\text { GTTGTGAACCTTGAGGTCCTAAG }\end{array}$ & 637 & 2014) \\
\hline
\end{tabular}

Table 2

PCR condition for three different primer sets targeting the $\mathrm{N}$ gene

\begin{tabular}{cccc}
\hline Step & Temperature & Time & Cycle \\
\hline Initial denaturation & $95^{\circ} \mathrm{C}$ & $1 \mathrm{~min}$ & $1 \times$ \\
Denaturation & $95^{\circ} \mathrm{C}$ & $15 \mathrm{sec}$ & \\
\cline { 2 - 4 } Annealing & $54^{\circ} \mathrm{C}\left(1 \mathrm{~F} \_16\right.$ and $\left.1 \mathrm{R} \_8\right)$ & \\
& $58^{\circ} \mathrm{C}(\mathrm{FN}-2 \mathrm{~F}$ and FN-2R $)$ & $1 \mathrm{~min}$ & $35 \times$ \\
Extension & $58^{\circ} \mathrm{C}(\mathrm{FN}-3 \mathrm{~F}$ and FN-3R $)$ & & \\
\cline { 2 - 4 } Final extension & $72^{\circ} \mathrm{C}$ & $1 \mathrm{~min}$ & $1 \times$ \\
Hold & $72^{\circ} \mathrm{C}$ & $5 \mathrm{~min}$ & $1 \times$ \\
\hline
\end{tabular}




\section{Phylogenetic Analysis}

The sequences from all seven isolates were aligned and trimmed using the MEGA $\mathrm{X}$ (version 10.0.05) software. Then, all sequences were compared with all available FeMV sequences in National Center for Biotechnology Information (NCBI) nucleotide databases using nucleotide basic local alignment search tool (BLAST). Partial sequences of $N$ gene FeMV-Malaysia isolates were subsequently subjected to phylogenetic tree construction, along with the other FeMV- $N$ gene sequences available in the GenBank using the MEGA
X software (Table 3). The phylogenetic tree was constructed using the Maximum Likelihood method with bootstrap values of 1,000 replicates based on the general timereversible (GTR) model. The construction of the phylogenetic tree also included other distantly-related viruses under the genus Morbillivirus, which were the canine distemper virus (CDV), peste des petits ruminants virus (PPRV), rinderpest virus (RPV), dolphin morbillivirus (DMV), phocine distemper virus (PDV), and measles virus $(\mathrm{MeV})$ as an outgroup comparison (Sakaguchi et al., 2014; Sieg et al., 2019).

Table 3

Viral strains included for phylogenetic tree construction

\begin{tabular}{lcccc}
\hline Species & Isolate & Year & Location & Accession number \\
\hline FeMV & 761U & 2012 & Hong Kong & JQ411014 \\
FeMV & 776U & 2012 & Hong Kong & JQ411015 \\
FeMV & M252A & 2012 & China & JQ411016 \\
FeMV & OtJP001 & 2014 & Japan & AB924120 \\
FeMV & MiJP003 & 2014 & Japan & AB924121 \\
FeMV & ChJP073 & 2014 & Japan & AB924122 \\
FeMV & SS1 & 2014 & Japan & AB910309 \\
FeMV & SS2 & 2015 & Japan & LC036586 \\
FeMV & SS3 & 2015 & Japan & LC036587 \\
FeMV & US1 & 2015 & USA & KR014147 \\
FeMV & Thai-U16 & 2017 & Thailand & MF627832 \\
FeMV & PIUMA/2015 & 2015 & Italy & KT825132 \\
FeMV & Tremedino & 2018 & Italy & MK088516 \\
FeMV & Pepito & 2018 & Italy & MK088517 \\
FeMV & Capitan Harlock & 2018 & Italy & MK188746 \\
FeMV & Nerina & 2018 & Italy & MK188747 \\
FeMV & Pedro & 2018 & Italy & MK188748 \\
FeMV & Sheryl & 2018 & Italy & MK188749 \\
FeMV & Rossino & 2018 & Italy & MK188750 \\
FeMV & Trezampe & 2018 & Italy & MK188751 \\
FeMV & Claudio & 2018 & Italy & MK188752 \\
FeMV & Tris & 2018 & Italy & MK188753 \\
FeMV & Lilly & 2018 & MK188754 \\
\hline
\end{tabular}


Table 3 (continue)

\begin{tabular}{lcccc}
\hline Species & Isolate & Year & Location & Accession number \\
\hline FeMV & TV17 & 2017 & Germany & MG563820 \\
FeMV & Gordon & 2018 & Germany & MK182089 \\
FeMV & TV25 & 2018 & Germany & MK182090 \\
FeMV & ZRU293/17 & 2018 & South Africa & MH813465 \\
FeMV & CTL16 & 2019 & Thailand & MN164531 \\
FeMV & CTL43 & 2019 & Thailand & MN164532 \\
CDV & CDV SY & 2012 & China & KJ466106 \\
PPRV & SnDk11I13 & 2013 & Africa & KM212177 \\
RPV & Kabete O & 1996 & Africa & NC006296 \\
DMV & 631IMM5031711 & 2011 & USA & KU720625 \\
PDV & PDV/USA 2006 & 2006 & USA & KY629928 \\
MeV & Ichinose-B95a & 1998 & USA & NC001498 \\
\hline
\end{tabular}

\section{RESULTS}

\section{DNA Sequencing Analysis and Basic Local Alignment Search Tool (BLAST) of $N$ Gene}

BLAST search analysis of partial $N$ gene of all seven FeMV-Malaysia isolates revealed high similarities with 29 FeMV isolates from other countries (81\%-99\%). All sequences have been submitted in the GenBank under accession numbers MN264638-MN264642, MN792827, and MN792828 (Table 4). In addition, high similarities were observed between FeMV-Malaysia isolates (98\%99\%) and FeMV isolates originated from Asian countries, such as Japan (LC036587), and Thailand (MN164531) (Table 5).

\section{Pairwise Alignment on $N$ gene of FeMV- Malaysia Isolates}

Multiple alignments of FeMV-Malaysia isolates detected in this study were performed to assess any significant nucleotide difference. There were 19 variable sites observed
Table 4

Genome submission to NCBI

\begin{tabular}{cc}
\hline Sample ID & Accession number \\
\hline UPM23 & MN264638 \\
UPM52 & MN264639 \\
UPM53 & MN264640 \\
UPM210 & MN264641 \\
UPM231 & MN264642 \\
UPM305 & MN792827 \\
UPM315 & MN792828 \\
\hline
\end{tabular}

out of 962 among the seven FeMV-N genes Malaysia isolates. However, none of these sites resulted in different amino acid residues except for isolate UPM210 and isolate UPM315 at positions 806 and 823, respectively (Figure 2). For UPM210, nucleotide change at position 806 resulted in amino acid serine compared to asparagine in other isolates. In contrast, amino acid valine was detected as a result of nucleotide change at position 823 for UPM315 isolate compared to amino acid isoleucine among the other six FeMV-Malaysia isolates. 
Table 5

Summary of BLAST search for partial FeMV-N gene sequences

\begin{tabular}{|c|c|c|c|}
\hline $\begin{array}{c}\text { Sample ID/ } \\
\text { Accession no. }\end{array}$ & $\begin{array}{c}\text { Identities } \\
\text { similarity } \mathrm{X} / \mathrm{Y}(\%)\end{array}$ & $\begin{array}{l}\text { Accession number } \\
\text { for reference strain }\end{array}$ & Remark for reference strain \\
\hline $\begin{array}{c}\text { UPM23 } \\
\text { MN264638 }\end{array}$ & $\begin{array}{l}1595 / 1608 \\
(99 \%)\end{array}$ & LC036587 & $\begin{array}{l}\text { Feline morbillivirus } N, P / V / C, M, F, H, L \text { genes } \\
\text { for nucleocapsid protein, phosphoprotein, } \\
\text { matrix protein, fusion protein, hemagglutinin, } \\
\text { protein, RNA polymerase, complete CDS, } \\
\text { strain: SS3 }\end{array}$ \\
\hline $\begin{array}{c}\text { UPM52 } \\
\text { MN264639 }\end{array}$ & $\begin{array}{l}1567 / 1584 \\
(99 \%)\end{array}$ & LC036587 & $\begin{array}{l}\text { Feline morbillivirus } N, P / V / C, M, F, H, L \text { genes } \\
\text { for nucleocapsid protein, phosphoprotein, } \\
\text { matrix protein, fusion protein, hemagglutinin, } \\
\text { protein, RNA polymerase, complete CDS, } \\
\text { strain: SS3 }\end{array}$ \\
\hline $\begin{array}{l}\text { UPM53 } \\
\text { MN264640 }\end{array}$ & $\begin{array}{l}1563 / 1578 \\
(99 \%)\end{array}$ & MN164531 & $\begin{array}{l}\text { Feline morbillivirus isolate CTL16, complete } \\
\text { genome }\end{array}$ \\
\hline $\begin{array}{l}\text { UPM210 } \\
\text { MN264641 }\end{array}$ & $\begin{array}{l}1565 / 1580 \\
(99 \%)\end{array}$ & MN164531 & $\begin{array}{l}\text { Feline morbillivirus isolate CTL16, complete } \\
\text { genome }\end{array}$ \\
\hline $\begin{array}{l}\text { UPM231 } \\
\text { MN264642 }\end{array}$ & $\begin{array}{c}1603 / 1618 \\
(99 \%)\end{array}$ & MN164531 & $\begin{array}{l}\text { Feline morbillivirus isolate CTL16, complete } \\
\text { genome }\end{array}$ \\
\hline $\begin{array}{l}\text { UPM305 } \\
\text { MN792827 }\end{array}$ & $\begin{array}{l}1547 / 1564 \\
(99 \%)\end{array}$ & LC036587 & $\begin{array}{l}\text { Feline morbillivirus } N, P / V / C, M, F, H, L \text { genes } \\
\text { for nucleocapsid protein, phosphoprotein, } \\
\text { matrix protein, fusion protein, hemagglutinin, } \\
\text { protein, RNA polymerase, complete CDS, } \\
\text { strain: SS3 }\end{array}$ \\
\hline $\begin{array}{c}\text { UPM315 } \\
\text { MN792828 }\end{array}$ & $\begin{array}{c}1587 / 1607 \\
(99 \%)\end{array}$ & MN164531 & $\begin{array}{l}\text { Feline morbillivirus isolate CTL16, complete } \\
\text { genome }\end{array}$ \\
\hline
\end{tabular}

Note. X: Total nucleotide similarities between FeMV- $N$ gene Malaysia isolates and FeMV- $N$ gene of reference strains in GenBank; Y: Total nucleotide of FeMV- $N$ gene of reference strains in GenBank; CDS: Coding DNA sequence

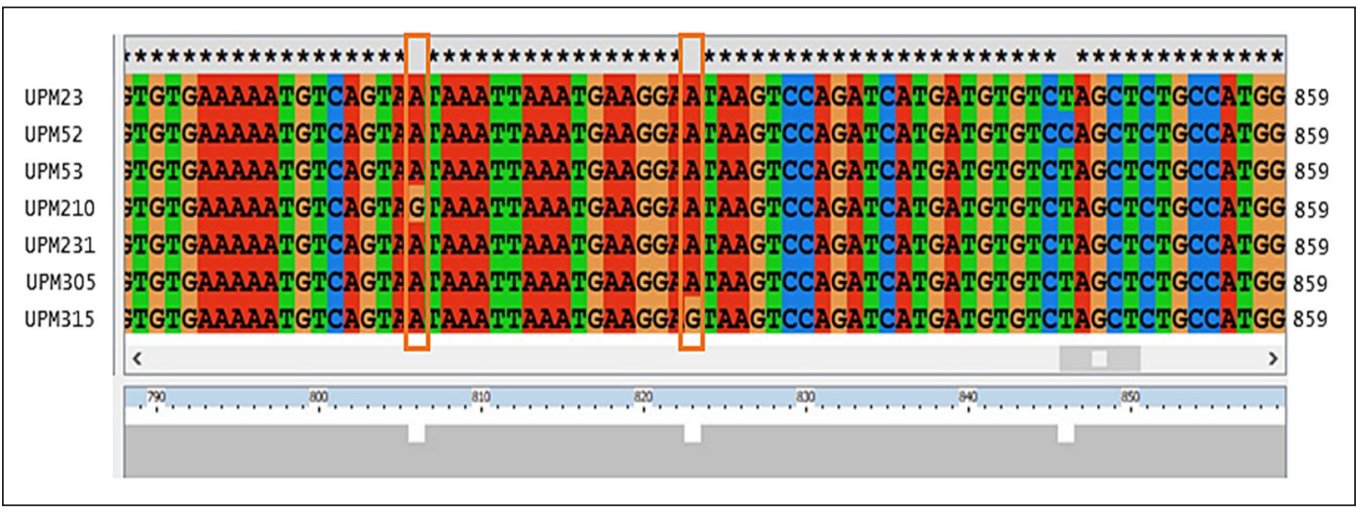

Figure 2. Multiple alignments of nucleotide detected in $N$ gene from FeMV-Malaysia isolates. Boxes indicate nucleotide differences for UPM210 and UPM315 at positions 806 and 823, respectively, among the sequenced FeMV-Malaysia isolates. The position of the nucleotides is at the bottom, while the number of nucleotides for each isolate is presented to the right of each isolate. The asterisk $(*)$ symbol represents identical nucleotides among the isolates 


\section{Nucleocapsid Protein Analysis}

In this work, 320 amino acids were successfully encoded, compared with 519 amino acids that should be encoded when a full $N$ gene is sequenced. One highly conserved sequence motif among paramyxoviruses from Sequence 3 was indicated in the red box in Figure 3. Comparison between amino acid residues for FeMV-Malaysia isolates and other FeMV isolates, along with species from the same genus of Morbillivirus, demonstrated consistent conserved amino acid residues (as underlined in Figure 3) in all species included in the alignment. In addition, the amino acid residue PPRV and RPV at position 328 was detected as alanine, whereas in other isolates, the amino acid at the same position was serine. Due to the nucleotide differences, wherein PPRV and RPV, nucleotide GCC was detected, compared with other isolates whereby nucleotide TCT was detected.

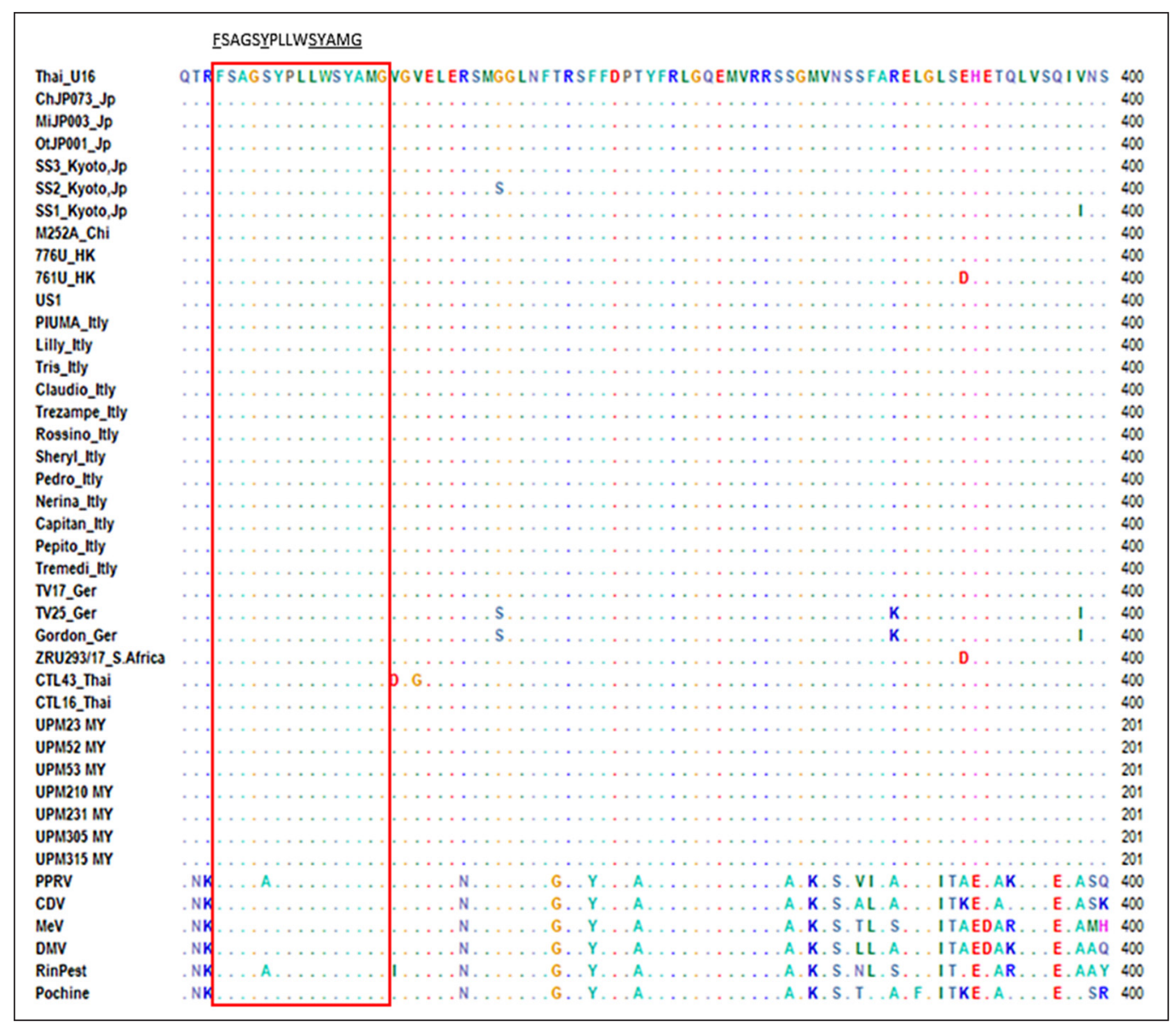

Figure 3. Multiple alignments of N protein amino acid residues of FeMV and other morbilliviruses sequences. Box indicates conserved motifs in paramyxoviruses. Amino acid residue numbers for each protein isolate are presented to the right of each isolate. Dots denote the identical amino acid residues between each protein isolate 


\section{Phylogenetic Tree Analysis of Partial FeMV-N Gene Sequences of Malaysia Isolates}

Phylogenetic analysis was conducted to review the evolutionary relationship between isolates from different countries. All partial FeMV-N gene Malaysia isolates (UPM210, UPM231, UPM305, and UPM315) showed $>99 \%$ identical sequence with the isolates detected in the previous study: UPM23, UPM52, UPM53; thus, these seven isolates were clustered together within the same clade (Figure 4). In addition, FeMV-Malaysia isolates showed a close relationship to isolates from Thailand (Thai-U16, CTL16, and CTL43) and China (M252A) with 98\% nucleotide similarities while sharing 98\%$99 \%$ nucleotide similarities with three of

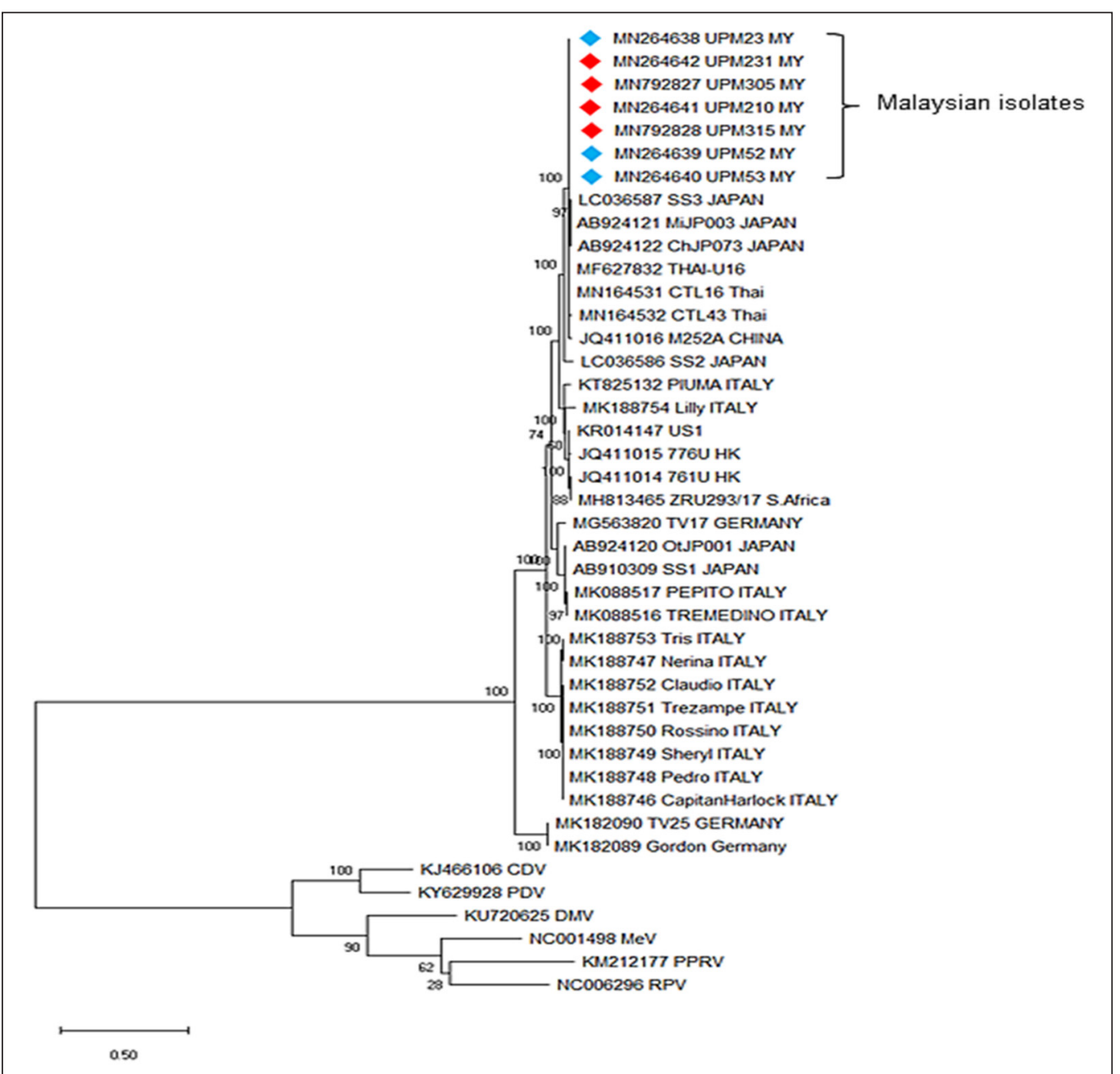

Figure 4. Phylogenetic analysis based on partial FeMV- $N$ gene sequences of Malaysia isolates. FeMV- $N$ gene Malaysia isolates detected in this study, which clustered together, are represented by red diamond shape $(\diamond)$ (Makhtar et al., 2021) and blue diamond shape $(\diamond)$ (Mohd Isa et al., 2019). The evolutionary analysis was constructed using the maximum likelihood method based on the general time-reversible model using MEGA $\mathrm{X}$ (version 10.0.05) software. The scale represents the number of substitutions per site 
Japan isolates (SS3, MiJP00, and ChJP073). However, the SS2 isolate from Japan showed only $94 \%$ nucleotide similarities with Malaysian isolates, of which it formed a different branch within the phylogenetic tree. Furthermore, comparing with BLAST search of nucleotide similarity result, it also can be noted that isolates (SS3 and CTL16) that recorded $>98 \%$ similarity with FeMV-N gene Malaysia isolates detected in this study were closely related to each other, illustrating a consistent finding with the outcome from BLAST search. In addition, another genotype of FeMV, FeMV genotype 2 (FeMV-GT2), established its cluster with two other isolates: TV25 and Gordon. All 29 FeMV isolates available in GenBank also formed a distinct clade separated from the outgroup isolates, comprising other members of the genus Morbillivirus.

\section{DISCUSSION}

Feline morbillivirus has been implicated as the cause of interstitial nephritis associated with chronic kidney disease in cats; however, further evidence is needed to prove Koch's postulate of FeMV infection (de Luca et al., 2021). Nevertheless, many countries have reported the occurrence of FeMV among cats; therefore, the importance of this virus should not be undermined. Upon successful detection of FeMV among cats in Malaysia, further characterization of these FeMV isolates is warranted. However, an attempt to obtain a full sequence of the FeMV- $N$ gene from this study had been unsuccessful, as none of the primer sets designed could amplify the leader region of the $N$ gene. Nevertheless, BLAST search and sequencing analyses of partial $N$ gene were performed on seven positive samples from previous studies: UPM23, UPM52, UPM53, UPM210, UPM231, UPM305, and UPM315 (Makhtar et al., 2021; Mohd Isa et al., 2019). Furthermore, a BLAST search showed a high similarity percentage between isolates obtained from a study by Makhtar et al. (2021) with previously detected FeMV-Malaysia isolates, as the samples were collected within the same geographical area. From the BLAST result of 29 FeMV isolates from other countries, a high similarity (98\%-99\%) was observed with FeMV isolates from China, Japan, and Thailand, indicating that FeMV isolates from Malaysia have been circulating in the Asian region. Besides that, the factor of Asian climate may also play a role in transmission and adaptation of the virus, which could contribute to the high similarity percentage among the isolates from Asian countries, compared with that from other countries (Wu et al., 2016).

Based on the nucleotide alignment of the partial $N$ gene of the seven FeMVMalaysia isolates, two different amino acid substitution site was detected, each one within isolate UPM210 and UPM315. This amino acid difference might be due to the position of the nucleotide where it lies at the structurally variable region of the $N_{\text {TAIL }}$ domain, which comprises approximately 120 to 150 amino acid residues (Communie et al., 2014). This finding is also in agreement with a study on FeMV-N protein by Woo et al. (2012), whereby at both positions (806 and 823), amino acid substitutions were 
detected among the FeMV isolates from China and Hong Kong. Even though RNA virus does frequently undergo mutation by approximately one mutation per virus genome copy to combat the host immune response, the mutation usually would not interfere with the essential virus function, and if it does, it will result in positive or negative selection, which leads to a superior mutation that enables the virus to survive despite the replication of the host immune response (Fleischmann, 1996). On the other hand, if the mutation damages the virus's essential function, a negative selection will occur, whereby the mutation will be deleted. Nevertheless, due to the redundancy of genetic code, most mutations are neutral, demonstrating no changes towards protein function, as the amino acid remains unchanged. However, to assess any mutation for the FeMV-Malaysia isolates, whole genome sequencing should be done to compute the pairwise alignment of FeMV isolates. This study focused only on $\mathrm{N}$ protein, so calculating the percentage of nucleotide similarities for the other five open reading frames (ORFs) for FeMV could not be accomplished. Based on the phylogenetic analysis, even though whole genome sequencing was not done, it is noteworthy that the FeMV-Malaysia isolates formed a distinct clade with the previously introduced new genotype of FeMV, FeMVGT2, which was detected in Germany (Sieg et al., 2019).

Nucleoprotein $(\mathrm{N})$ comprises of the $N_{\text {CORE }}$ which is the $\mathrm{N}$-terminal moiety covering the first 400 amino acids of $\mathrm{N}$ protein and the $N_{\text {TAIL }}$ domain which is the
C-terminal moiety (Thakkar et al., 2018). $N_{\text {CORE }}$ is responsible for RNA encapsidation, a prerequisite for viral RNA synthesis. Amino acid analyses identified conserved motifs within the Paramyxovirinae, which are Region 1, 172-QxW(I,V)xxxK(A,C) xT-184; Region 2, 268-FxxT(I,L)(R,K) $\Omega(\mathrm{G}, \mathrm{A})(\mathrm{L}, \mathrm{I}, \mathrm{V}) \times \mathrm{T}-280$; and Region 3, 323- FxxxxYPxx $\Omega S \Omega A M G-339$, where $\mathrm{x}$ indicates any amino acid residue, $\Omega$ indicates an aromatic amino acid residue, and either one of the residues in parentheses (Morgan, 1991). On the other hand, the interaction of $\mathrm{N}$ and $\mathrm{P}$ proteins is mediated by the $N_{\text {TAIL }}$ region of approximately 120 to 150 amino acids of the structurally variable region (Communie et al., 2014). During the initial stage of infection, the RNA-dependent RNA polymerase (RdRp) complex will only recognize and synthesize viral RNA, which is encapsidated by $\mathrm{N}$ protein as a template (Sourimant \& Plemper, 2016). Although the $N$ gene is quite conserved compared to the $F$ and $H$ genes, given the importance during early infection, the characterization of the $N$ gene may give further insight into the newly emerging FeMV infection in cats.

However, from the three highly conserved regions of the $\mathrm{N}$ protein, only one conserved region was obtained in this study. The conserved sequence (amino acid residue at a position between 324-328) showed a similar amino acid residue in alignment with 29 other FeMV isolates from different countries, consistent with a previous study (Woo et al., 2012). Moreover, within the conserved Region 3, a different amino acid residue, alanine (A), was detected in RPV and PPRV at position 
328, whereas other isolates resulted in serine $(\mathrm{S})$ amino acid residue. However, there was little information on whether the amino acid difference played a significant role in RNA binding and forming the helical nucleocapsid; hence, there is a need for future in vitro study elucidating the effects of amino acid changes towards the nucleocapsid role. In addition, the full $\mathrm{N}$ protein sequence analysis is warranted by designing a primer set that targets the leader region.

\section{CONCLUSION}

Sequences of $\sim 1.5 \mathrm{~kb}$ from seven FeMVMalaysia isolates were obtained through conventional RT-PCR detection from selected urine samples. A BLAST search of the partial $N$ gene of FeMV-Malaysia isolates (UPM23, UPM52, UPM53, UPM210, UPM231, UPM305, and UPM315) revealed to have had a high percentage of nucleotide similarities with isolates from Japan (SS3) and Thailand (CTL16). From phylogenetic analysis, the seven FeMV-Malaysia isolates are clustered together with other Asian countries, such as Thailand (Thai-U16, CTL43, CTL16) and Japan (SS3, MiJP003, ChJP073). In addition, nucleotide alignment of the seven FeMV-Malaysia isolates detected 19/962 variable sites, of which only two isolates, UPM210 and UPM315, had amino acid substitution. From the alignment of amino acid residues of FeMVisolates and other morbilliviruses, consistent amino acid residues were observed in one of the conserved regions in morbilliviruses. Therefore, to assess for any genetic change, it is suggested to perform sequence alignments and phylogenetic analysis from other genes, especially on $F$ and $H$ genes, which are more heterogeneous and prone for recombination.

\section{ACKNOWLEDGMENTS}

This study was funded by Universiti Putra Malaysia under the Inisiatif Putra Siswazah grant (Grant No.: GP-IPS/2017/9536900). The authors would like to thank Mr. Megat Hamzah Megat Mazhar Khair for his kind assistance in primer design and the veterinarians involved in collecting samples sequenced in this study.

\section{REFERENCES}

Communie, G., Ruigrok, R. W., Jensen, M. R., \& Blackledge, M. (2014). Intrinsically disordered proteins implicated in paramyxoviral replication machinery. Current Opinion in Virology, 5(1), 7281. https://doi.org/10.1016/j.coviro.2014.02.001

de Luca, E., Sautto, G. A., Crisi, P. E., \& Lorusso, A. (2021). Feline morbillivirus infection in domestic cats: What have we learned so far?. Viruses, 13(4), 683. https://doi.org/10.3390/v13040683

Fleischmann, W. R. (1996). Viral genetics. In S. Baron (Ed.), Medical microbiology (4th ed., p. 43). University of Texas Medical Branch.

Makhtar, S. T., Tan, S. W., Nasruddin, N. A., Abdul Aziz, N. A., Omar, A. R., \& Mustaffa-Kamal, F. (2021). Development of TaqMan-based realtime RT-PCR assay based on $N$ gene for the quantitative detection of feline morbillivirus. BMC Veterinary Research, 17(1), 128. https:// doi.org/10.1186/s12917-021-02837-6

Mohd Isa, N. H., Selvarajah, G. T., Khor, K. H., Tan, S. W., Manoraj, H., Omar, N. H., Omar, A. R., \& Mustaffa-Kamal, F. (2019). Molecular detection and characterisation of feline morbillivirus 
in domestic cats in Malaysia. Veterinary Microbiology, 236, 108382-108382. https://doi. org/10.1016/j.vetmic.2019.08.005

Morgan, E. M. (1991). Evolutionary relationships of Paramyxovirus nucleocapsid-associated proteins. In D. W. Kingsbury (Ed.), The Paramyxoviruses (pp. 163-179). Springer. https://doi.org/10.1007/978-1-4615-3790-8_5

Park, E. S., Suzuki, M., Kimura, M., Maruyama, K., Mizutani, H., Saito, R., Kubota, N., Furuya, T., Mizutani, T., Imaoka, K., \& Morikawa, S. (2014). Identification of a natural recombination in the $F$ and $H$ genes of feline morbillivirus. Virology, 468-470, 524-531. https://doi.org/10.1016/j. virol.2014.09.003

Rima, B., Balkema-Buschmann, A., Dundon, W. G., Duprex, P., Easton, A., Fouchier, R., Kurath, G., Lamb, R., Lee, B., Rota, P., Wang, L., \& Ictv Report, C. (2019). ICTV virus taxonomy profile: Paramyxoviridae. Journal of General Virology, 100(12), 1593-1594. https://doi.org/10.1099/ jgv. 0.001328

Sakaguchi, S., Nakagawa, S., Yoshikawa, R., Kuwahara, C., Hagiwara, H., Asai, K. I., Kawakami, K., Yamamoto, Y., Ogawa, M., \& Miyazawa, T. (2014). Genetic diversity of feline morbilliviruses isolated in Japan. Journal of General Virology, 95(7), 1464-1468. https://doi. org/10.1099/vir.0.065029-0

Sieg, M., Busch, J., Eschke, M., Böttcher, D., Heenemann, K., Vahlenkamp, A., Reinert, A., Seeger, J., Heilmann, R., Scheffler, K., \& Vahlenkamp, T. W. (2019). A new genotype of feline morbillivirus infects primary cells of the lung, kidney, brain and peripheral blood. Viruses, 11(2), 146. https://doi.org/10.3390/v11020146

Sourimant, J., \& Plemper, R. K. (2016). Organization, function, and therapeutic targeting of the morbillivirus RNA-dependent RNA polymerase complex. Viruses, 8(9), 251. https://doi. org/10.3390/v8090251

Thakkar, V. D., Cox, R. M., Sawatsky, B., da Fontoura Budaszewski, R., Sourimant, J., Wabbel, K., Makhsous, N., Greninger, A. L., von Messling, V., \& Plemper, R. K. (2018). The unstructured paramyxovirus nucleocapsid protein tail domain modulates viral pathogenesis through regulation of transcriptase activity. Journal of Virology, 92(8), e02064-17. https://doi.org/10.1128/ jvi.02064-17

Woo, P. C., Lau, S. K., Wong, B. H., Fan, R. Y., Wong, A. Y., Zhang, A. J., Wu, Y., Choi, G. K., Li, K. S., Hui, J., Wang, M., Zheng, B. J., Chan, K. H., \& Yuen, K. Y. (2012). Feline morbillivirus, a previously undescribed paramyxovirus associated with tubulointerstitial nephritis in domestic cats. Proceedings of the National Academy of Sciences of the United States of America, 109(14), 5435-5440. https:// doi.org/10.1073/pnas.1119972109

Wu, X., Lu, Y., Zhou, S., Chen, L., \& Xu, B. (2016). Impact of climate change on human infectious diseases: Empirical evidence and human adaptation. Environment International, 86, 1423. https://doi.org/10.1016/j.envint.2015.09.007 
